Document downloaded from:

http://hdl.handle.net/10251/80977

This paper must be cited as:

Desantes Fernández, JM.; Bermúdez, V.; López, JJ.; López Pintor, D. (2016). Experimental validation of an alternative method to predict high and low-temperature ignition delays under transient thermodynamic conditions for PRF mixtures using a Rapid CompressionExpansion Machine. Energy Conversion and Management. 129:23-33. doi:10.1016/j.enconman.2016.09.089.

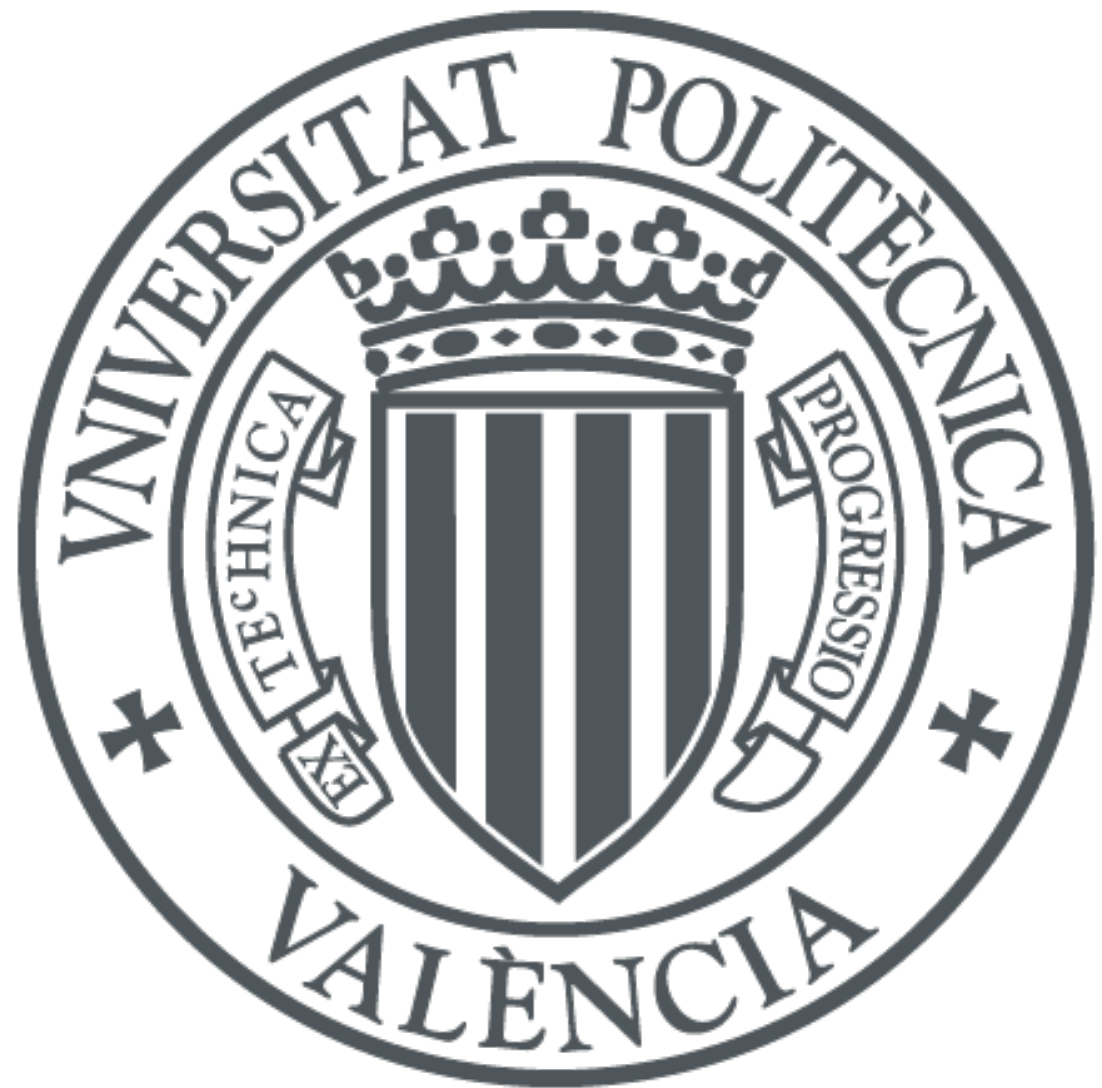

The final publication is available at

http://dx.doi.org/10.1016/j.enconman.2016.09.089

Copyright Elsevier

Additional Information 


\title{
Experimental validation of an alternative method to predict high and low-temperature ignition delays under transient thermodynamic conditions for PRF mixtures using a Rapid Compression-Expansion Machine
}

\author{
José M. Desantes ${ }^{\mathrm{a}}$, Vicente Bermúdez ${ }^{\mathrm{a}}$, J. Javier López ${ }^{\mathrm{a}, *}$, Darío \\ López-Pintor ${ }^{\mathrm{a}}$ \\ ${ }^{a}$ CMT-Motores Térmicos \\ Universitat Politècnica de València \\ Camino de Vera, s/n. 46022 Valencia, SPAIN
}

\begin{abstract}
An alternative procedure to predict both high-temperature stage and cool flames ignition delays under transient thermodynamic conditions is intended to be validated in this paper. An experimental study has been carried out in a Rapid Compression-Expansion Machine (RCEM), using different isooctane/n-heptane blends in order to cover a wide range of octane numbers (from 25 to 75 ) under a wide range of initial temperatures (from $363 \mathrm{~K}$ to $423 K$ ), compression ratios (14 and 19 ), $\mathrm{O}_{2}$ molar rates (from $21 \%$ to $16 \%$ ) and equivalence ratios (from 0.4 to 0.8 ). The results obtained have been used to validate direct chemical kinetic simulations, as well as to evaluate the alternative predictive method and the Livengood \& Wu integral method. Simulations have been performed solving a detailed chemical kinetic mechanism in CHEMKIN. The experimental results show good agreement with
\end{abstract}

\footnotetext{
${ }^{*}$ Corresponding author

Tel: +34963 879 232. Fax: +34 963877659 . E-mail: jolosan3@mot.upv.es
} 
the chemical kinetic simulations and with the alternative predictive method. In fact, the mean relative deviation between experiments and simulations is equal to $1.7 \%, 2.2 \%$ and $3.1 \%$ for PRF25, PRF50 and PRF75, respectively. Besides, the alternative method has shown good predictive capability not only for the high-temperature stage of the process, but also for cool flames, being the mean relative deviation versus the experimental data lower than $3.3 \%$ for all fuels. Better predictions of the ignition delay have been obtained with the alternative procedure than the ones obtained with the classic Livengood \& Wu expression, especially in those cases showing a two-stage ignition pattern, in which the Livengood \& Wu integral method is not able to predict the high-temperature stage of the process.

Keywords: RCEM, ignition delay, autoignition modeling, fuels, chemical processes

\section{Introduction, justification and objective}

Regulations about pollutant emissions in internal combustion engines 3 have become increasingly restrictive during the last years. Moreover, this 4 trend is not only present in automotive engines, but also for naval and sta5 tionary engines. New European emission standards (Euro VI) for heavy-duty vehicles equipped with diesel engines, for instance, have reduced the $\mathrm{NO}_{x}$ limits in $80 \%$, while the maximum soot emissions have been reduced in $50 \%$. Since both $\mathrm{NO}_{x}$ and soot emissions cannot be simultaneously reduced in conventional diesel combustion and due to the high cost of after-treatment systems for such pollutant species, new combustion strategies have appeared as an alternative method to achieve simultaneously clean and efficient en- 
gines.

Advanced combustion modes based on the autoignition of a premixed mixture with a certain degree of homogeneity have been studied for the simultaneous reduction of soot and $\mathrm{NO}_{x}$ [1]. Their working principle is based on Low Temperature Combustion (LTC) by avoiding the soot and $\mathrm{NO}_{x}$ formation peninsulas, which can be seen in equivalence ratio - temperature diagrams [2], and their effectiveness has been proved in several studies [3]. Despite the fact that these combustion modes show virtually zero emissions of $\mathrm{NO}_{x}$ and soot, they are characterized by high emissions of carbon monoxide (CO) and unburned hydrocarbons (UHC), which can be easily eliminated with well-known after-treatment techniques.

Two main challenges appear with the implementation of these advanced combustion strategies in commercial engines: the lack of control over the autoignition process and, therefore, over the heat release rate [4]; and the operating range, which is limited to low-to-medium loads [5]. On the one hand, ignition is controlled by the chemical kinetics of the charge in these combustion modes [6]. This control entails higher complexity since there is not any explicit ignition-controlling available, such as direct injection process near top dead center or a spark. The reactivity of the mixture is modified by adjusting the engine operating conditions, including the Exhaust Gas Recirculation (EGR) rate and the inlet temperature. Therefore, improving the capability of predicting the autoignition is mandatory to properly modify the settings of the engine in order to control the heat release. On the other hand, the operating range in LTC modes is restricted to low-to-medium loads due to the fast combustion velocity of the autoignition event when the engine 
load is increased, which results in high pressure rise rates and, therefore, in high combustion noise and mechanical strains.

The autoignition phenomenon can be well predicted by using advanced CFD codes with detailed chemistry and long computing times. Thus, the computational cost is too high for the implementation of such methodologies in an engine control unit, in which only simple numerical methods can be implemented. If these low computing time predictive methods have enough accuracy on the prediction of the ignition delay, the control of the engine can be significantly improved since decisions in real time can be taken. The Livengood \& Wu integral method [7] allows to obtain ignition delays of processes under transient thermodynamic conditions by using the ignition times at constant temperature and pressure conditions, which can be obtained experimentally and by simulation, and easily parameterized. The expression proposed by these authors is the following:

$$
\int_{0}^{t_{i}} \frac{1}{\tau} d t=1
$$

where $t_{i}$ is the time of ignition of the process and $\tau$ is the ignition delay time under constant conditions for the successive thermodynamic states.

The Livengood \& Wu integral defined the ignition event as the instant at which a critical concentration of chain carriers is reached, assuming that the critical concentration is constant whatever the thermodynamic conditions for a certain air-fuel mixture. Besides, the integral method describes the decomposition of the fuel during the ignition delay by a single zero-order global reaction that cannot properly model the negative temperature coefficient (NTC) behavior. This predictive method has been enunciated as a 
characterization of knock in SI-engines [8]. However, nowaday it has become more relevant for CI-engines, in which it can be used as a method for the prediction of the ignition characteristics of homogeneous mixtures as the ones used in LTC combustion modes [9]. Several authors such as Ohyama [10], Rausen et al. [11], Choi et al. [12] and Hillion et al. [13] studied the implementation of the Livengood \& Wu integral method in an engine control unit. The integral method has been used to predict the ignition event under HCCI conditions, so that it can be combined with some other simple models to characterize the combustion process, allowing the control of the engine in real time.

Since the Livengood \& Wu integral method is based on a single global reaction mechanism that ignores the cool flames and the NTC behavior, it seems to not be able to accurately predict the ignition delay when a twostage ignition occurs, as it has been wondered by several authors [14]. Some of these authors, as Liang and Reitz [15] or Edenhofer et al. [16], show the need to propose simple numerical methods to predict the ignition time in a simple way and with low computational cost, but avoiding the most restrictive hypotheses of the integral method, in order be able to characterize the low-temperature autoignition phenomenon avoiding any chemical kinetic mechanism. However, few alternative predictive methods can be found in the literature.

Hernandez et al. [17] studied the accuracy of the Livengood \& Wu integral by solving different chemical kinetic mechanisms for different fuels by simulation in CHEMKIN. They checked that, if the fuel follows a single-stage ignition pattern, quite good prediction capability is shown by the integral 
method. Two alternative procedures have been proposed by these authors, resulting one of them in better results than the Livengood \& Wu integral. However, the same hypotheses than the integral method are assumed in most of the alternative procedures proposed, since they are based on the Livengood $\& \mathrm{Wu}$ integral itself.

Desantes et al. $[18,19]$ have proposed different methods based on the Glassman's model to predict ignition delays referred to a critical concentration of chain carriers. The hypothesis of constant critical concentration is avoided in both methods, whereas one of them also avoids the description of the autoignition process by a single zero-order global reaction. However, since the ignition delay is defined as the time when a critical concentration of chain carriers is reached, only ignition delays referred to critical concentrations can be predicted accurately. Therefore, the high exothermic phase of the ignition cannot be obtained, since the critical concentration occurs in a previous stage. Desantes et al. [20] have also proposed an alternative method to predict both high-temperature stage and cool flames ignition delays under transient thermodynamic conditions, which is a previous work related to the current one. This alternative method has been validated for pure n-heptane and pure iso-octane. However, both fuels define the extreme values of the octane number reference scale and a wider validation among all the octane number scale is needed for a better evaluation of the predictive method.

Dual-fuel combustion based on diesel/gasoline mixtures has shown to be a good method to increase the operating range of LTC modes. Bessonette et al. [21] have shown that different in-cylinder reactivities are required for a proper LTC operation under different working conditions. Specifically, low 
octane fuels are required at low loads, while high octane fuels are needed at medium-to-high loads. A wide range of octane numbers can be achieved by using premixed gasoline mixtures in which a direct diesel injection causes an stratification of reactivities [1]. Thus, a flexible operation over a wide operating range is possible by modifying both the blending ratio between fuels and the direct injection settings. Therefore, predictive methods to improve the engine control should be validated not only for diesel and gasoline surrogate fuels, but also for a wide range of reactivities (i.e. of octane numbers).

The validity of an alternative procedure to determine both high-temperature and cool flames ignition delays under transient conditions is intended to be solved in this work for a wide range of octane numbers. The study has been done with different n-heptane and iso-octane blends, the reactivities of which are very similar to diesel fuel and gasoline, respectively. These Primary Reference Fuels blends (PRFs) are used to define the octane number reference scale. More specifically, PRF25 (25\% iso-octane), PRF50 (50\% iso-octane) and PRF75 (75\% iso-octane) have been evaluated in this work, which octane numbers are equal to 25,50 and 75, respectively. Besides, PRFs mixtures were chosen because extended and fully validated chemical kinetic mechanisms are available for them.

Simulations have been performed with the software of chemical simulation CHEMKIN (Reaction Design, ANSYS), which is consolidated in engineering investigations, so that the oxidation paths of several hydrocarbons are described by chemical kinetics mechanisms ready to be used with it. Finally, the numerical results are validated experimentally using a Rapid CompressionExpansion Machine (RCEM). 
The structure of the paper is the following: first, the experimental facility (RCEM) that has been used in this work is described. Then, the methodological approach is presented, including the experimental methods, the alternative predictive procedure, the chemical kinetic simulations and the parametric study performed. Afterwards, the experimental ignition delays are analyzed, the predictive method is validated with the experimental results and its predictive ability is compared with the chemical kinetic simulations and with other methods. Finally, the conclusions of this study are shown.

\section{Materials and methods}

An alternative method to predict ignition delays proposed by Desantes et al. [20] was tested by comparison with the experimental results from a RCEM. For a certain case, the in-cylinder temperature and pressure were experimentally obtained under motoring conditions (without combustion). Then, the ignition characteristics for each thermodynamic state (ignition delay, $\tau$, and critical concentration, $[C C]_{\max }$ ) were obtained by simulation in CHEMKIN solving a detailed mechanism in a perfectly stirred reactor. The ignition delay under transient thermodynamic conditions was measured directly form the experiments in the RCEM. Besides, it was also simulated in CHEMKIN solving the same detailed mechanism in an internal combustion engine reactor (direct chemical simulation). This ignition time is finally predicted by using the alternative procedure analyzed in this paper and the Livengood \& Wu integral method. Finally, the simulated and predicted ignition delays were compared with the experimental measurements. 


\begin{tabular}{|l|l|}
\hline 1 & Pushing piston \\
\hline 2 & Driver piston \\
\hline 3 & Displacement piston \\
\hline 4 & Air piston \\
\hline 5 & Combustion chamber \\
\hline
\end{tabular}

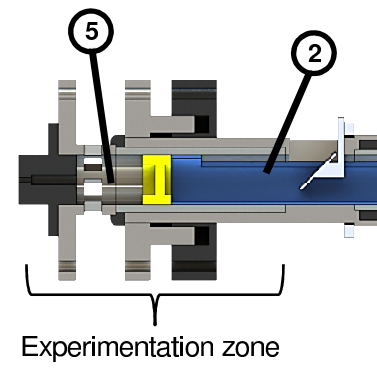

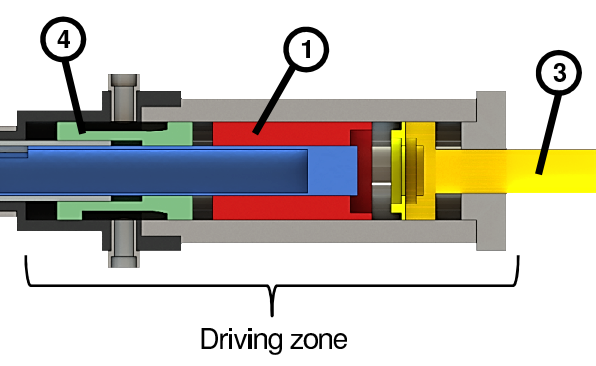

Figure 1: Rapid Compression Expansion Machine schematic.

\subsection{RCEM}

An RCEM is an useful experimental facility widely used in combustion studies due to its capability to replicate engine conditions under fully controlled initial and boundary conditions [22]. Not only the in-cylinder engine thermodynamic conditios can be replicated, but also the combustion phenomenon, while avoiding the complexities associated to engines [23].

Stroke and clearance volume can be modified in order to reproduce different engine geometrical characteristics, resulting in the capability of working with a wide range of compression ratios. Besides, the engine speed can be simulated by changing the compression velocity. A full diagnosis of the combustion process under engine conditions can be carried out, since not only the compression, but also the expansion stroke is replicated. Despite the fact that homogeneous mixtures are usually tested in autoignition studies to be able to trace the chemical kinetics in a easier way, heterogeneous mixtures can be also studied in this facility by injecting the fuel during the compression stroke, as well as new combustion modes such as the dual fuel technology [24] or LTC modes [25]. 
Figure 1 shows a schematic of the RCEM, in which two different zones can be distinguish: an experimentation zone and a driving zone. Four pistons compose the driving section. The pushing piston is pneumatically driven by the compressed air contained in the air piston and hydraulically coupled to the driver piston, which compresses the test sample into the combustion chamber. The stroke is selected by changing the position of the displacement piston, which is hydraulically driven. A wide explanation about the operation principle of the RCEM can be read in [19].

\begin{tabular}{|l|ll|}
\hline Bore & 84 & $\mathrm{~mm}$ \\
\hline Stroke & $120-249$ & $\mathrm{~mm}$ \\
\hline Compression ratio & $5-30$ & - \\
\hline Maximum cylinder pressure & 200 & bar \\
\hline Initial pressure & $1-5$ & bar \\
\hline Maximum heating temperature & 473 & $\mathrm{~K}$ \\
\hline
\end{tabular}

Table 1: Technical characteristics of the RCEM. cylindrical bowl, $46 \mathrm{~mm}$ in bore and $17 \mathrm{~mm}$ in depth.

The initial temperature, as well as the temperature of the walls, are con- 
trolled by a PID regulator that acts over an electrical $80 \mathrm{~W}$ heater located in the bowl and two more spire-shape electrical heaters (600 W each) located in the liner. the control loop is possible by measuring the temperature by three thermocouples located in the liner, in the piston and in the bowl, respectively. The intake and exhaust pipes, which are located in the liner, are designed to induce a swirl motion into the combustion chamber during the intake process. A homogeneous environment is guaranteed by the high level of turbulence generated during the filling, being the initial temperature equal to the wall temperature (checked by previous CFD studies). A Kistler 6045A uncooled piezoelectric pressure sensor located in the cylinder head (-45 $p C /$ bar of sensitivity) is coupled to a Kistler 5018 charge amplifier for the measurement of the in-cylinder pressure. Besides, the filling of both, the combustion chamber and the driving gas volume are controlled by three Wika piezoresistive pressure sensors (0.01 bar of resolution). Finally, a common rail system that includes a 7-hole nozzle implemented in a BOSCH solenoidcommanded injector that is controlled by a EFS IPod power driving module forms the injection system, which has been characterized as explained in [26]. A Yokogawa DL850V system composed by one $10 \mathrm{MHz}-12$ bits module and five more $1 M H z-16$ bits modules with two channels each acts as acquisition system, in which $10 \mathrm{MHz}$ are fixed as acquisition frequency. Such a high acquisition frequency is mandatory to be able to measure the electrical pulses of the incremental position sensor. However, both, in-cylinder and injection pressures are recorded at $1 \mathrm{MHz}$.

A heated external tank (up to $5204 \mathrm{~K}$ by three electrical heaters, $1200 \mathrm{~W}$ each) is used for the generation of the synthetic air, which is produced by 
mixing $\mathrm{N}_{2}, \mathrm{CO}_{2}$ and $\mathrm{O}_{2}$ according to their partial pressures. Moreover, $\mathrm{H}_{2} \mathrm{O}$ can be added thanks to a syringe pump. Vacuum is created before generating each mixture and before filling the RCEM to ensure the no contamination in this tank, nor in the combustion chamber. Finally, the exact composition of the synthetic mixture is measured by gas chromathography in a Rapid Refinery Gas Analyser from Bruker (450-GC) in order to ensure the correct reproduction of the experiments in CHEMKIN.

Figure 2 shows the move law of the RCEM compared to an engine. It can be seen that both paths are really similar around TDC. Besides, the pressure signal under motoring conditions is also plotted in the figure. The time reference $(t=0)$ is taking as the instant at which the piston position reaches $29 \mathrm{~mm}$, since it coincides with the start of the rapid compression stroke because of constructive aspects of the RCEM [19].

In this study, the synthetic EGR was considered to be composed by the products of a dry air/fuel complete combustion reaction in which the oxygen content is the one selected by the user, as explained in [27]. In order to avoid stratification problems, the fuel is injected into the combustion chamber at the beginning of the intake process, in which the turbulence generated, as well as the duration time $(\approx 40 s)$, are enough to guarantee a homogeneous environment when the compression stroke starts.

The ignition of the mixture is defined as the maximum time derivative of the pressure signal (pressure rise rate), so that the experimental ignition delay is defined as the time between the start of the rapid compression process, which is unambiguously defined because of constructive aspects of the machine, and the instant in which the maximum pressure rise is measured. An 


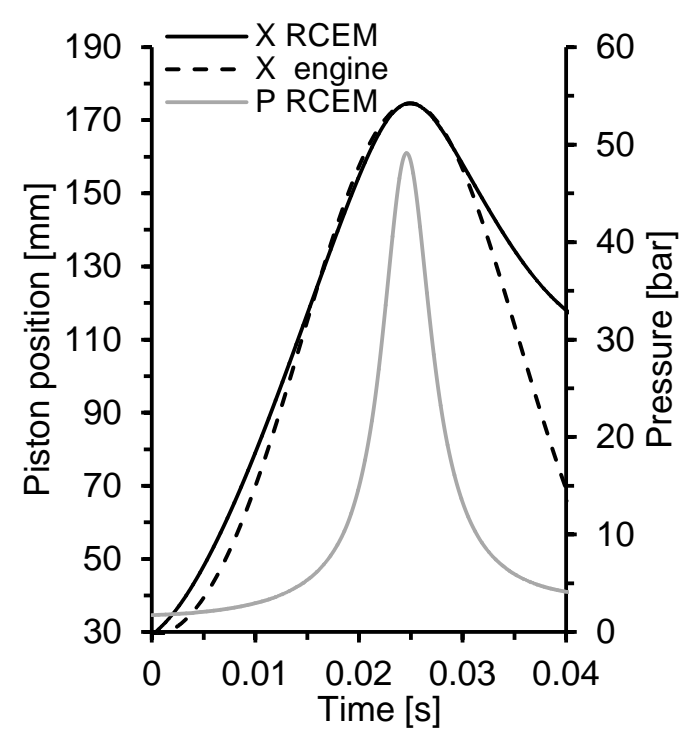

Figure 2: Move law of the RCEM compared to an engine and pressure path under motoring conditions.

example of the ignition delay definition can be seen in Fig. 3, in which cool flames and the high temperature ignition delay can be distinguished when a two-stage ignition pattern occurs. Furthermore, the number of repetitions for each operating condition has been selected so that the semi-amplitude of the confidence interval with a level of confidence of $95 \%$ is smaller than $1 \%$ of the mean ignition delay value. Thus, a representative ignition delay time measurement is ensured.

Finally, the temperature profile is calculated by solving the equation of state, in which the in-cylinder pressure and the piston position are measured. Furthermore, a model for deformations and another one for leaks (explained in $[28,29])$ are taken into account. The heat losses, which are needed to replicate the experiments in CHEMKIN, are characterized by a model based 


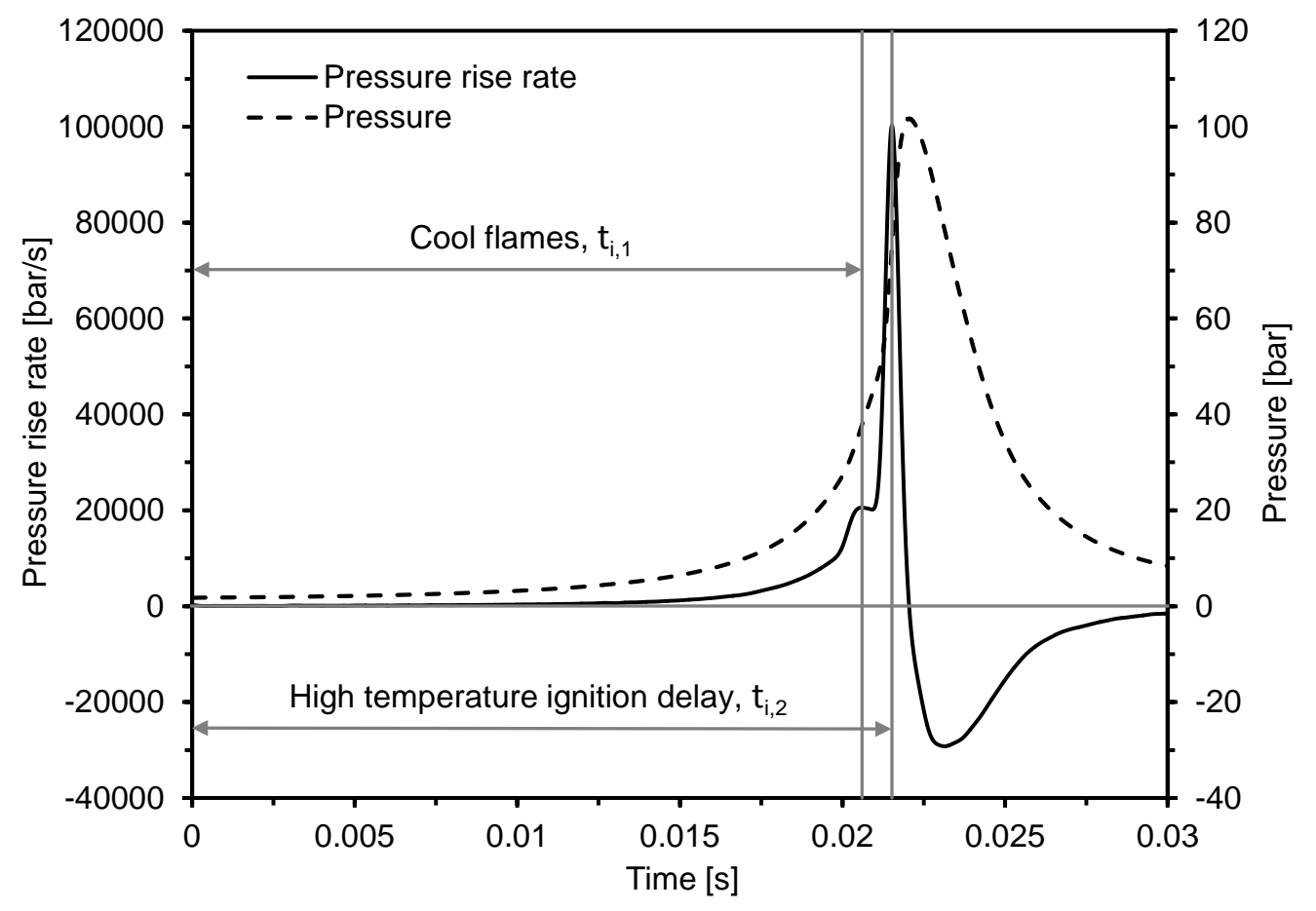

Figure 3: Ignition delay definition. The autoignition of the mixture is considered to be produced when the maximum pressure rise occurs. 
on the Woschni correlation [30].

\subsection{Alternative predictive method for ignition delays}

The predictive procedure proposed by Desantes et al. [20] is composed by two different consecutive integrals:

$$
\begin{aligned}
& 1=\frac{1}{[C C]_{\max , t_{i, C C}}} \int_{0}^{t_{i, C C}} \frac{[C C]_{\max }}{\tau_{C C}} d t \\
& 1=\frac{1}{[C C]_{\max , t_{i, C C}}} \int_{t_{i, C C}}^{t_{i, 2}} \frac{[C C]_{\text {max }}}{\tau_{2}-\tau_{C C}} d t
\end{aligned}
$$

where $t_{i, C C}$ is the ignition delay of the process referred to a maximum concentration of chain carriers and $t_{i, 2}$ is the ignition delay referred to the hightemperature stage of combustion. Besides, $\tau_{2}, \tau_{C C}$ and $[C C]_{\max }$ are the ignition delay referred to the high exothermic stage, the ignition delay referred to a maximum of chain carriers and the critical concentration of chain carriers, respectively, under constant conditions of pressure and temperature for the successive thermodynamic states.

The method is decoupled in two steps depending on the stage of the ignition to predict. On the one hand, a predictive method for cool flames is based on the accumulation of chain carriers up to reach the critical concentration. $\mathrm{HO}_{2}$ is selected as chain carrier since it seems to be a good tracer of such phenomenon $\left(C C=\mathrm{HO}_{2}\right)$. The accumulation of $\mathrm{HO}_{2}$ is modeled by Eq. 2, in which $\tau_{C C}$ and $[C C]_{\max }$ are related with this species. The upper limit of the integral represents the instant at which the maximum concentration of $\mathrm{HO}_{2}$ occurs, which corresponds to the ignition delay referred to cool flames.

On the other hand, a predictive method for the high-temperature stage of the combustion process is based on the accumulation of chain carriers up 
to the critical concentration (Eq. 2), and the subsequent consumption from this maximum of concentration (Eq. 3). Thus, two different consecutive integrals have to be solved in this method. $\mathrm{CH}_{2} \mathrm{O}$ is selected as chain carrier $\left(C C=\mathrm{CH}_{2} \mathrm{O}\right)$, since formaldehyde is widely recognized as an autoignition tracer and the maximum heat realease rate occurs when this species is almost consumed [31]. The instant at which the maximum concentration of $\mathrm{CH}_{2} \mathrm{O}$ is reached is obtained by solving Eq. 2, whereas the consumption of $\mathrm{CH}_{2} \mathrm{O}$ is modeled by Eq. 3. Obviously, $\tau_{C C}$ and $[C C]_{\max }$ have to be related with this species. The upper limit of the integral in Eq. 3 represents the time at which all formaldehyde is consumed, which corresponds to the ignition delay referred to the high-temperature stage.

A detailed description about the theoretical development that defines the method can be found in $[19,20]$.

\subsection{CHEMKIN and chemical kinetic mechanisms}

CHEMKIN-PRO is the software used to obtain the different ignition delays and critical concentrations. The Curran's kinetic mechanism, which is compsoed by 1034 species and 4238 reactions, is used for n-heptane/isooctane blends $[32,33]$. This mechanism includes the chemical kinetics of the two pure hydrocarbons that form the blends used in this investigation, the validity of which has been checked in different papers by comparison with experimental results $[34,35]$.

Different ignition delays are defined in the simulations:

- $\tau_{1}$ is the ignition delay under constant thermodynamic conditions referred to the maximum pressure rise caused by cool flames. 
- $\tau_{2}$ is the ignition delay under constant thermodynamic conditions referred to the maximum pressure rise caused by the high-temperature stage of the combustion process.

- $\tau_{C C}$ is the ignition delay under constant thermodynamic conditions referred to the critical concentration of chain carriers. Different species are proposed as chain carrier depending on the stage of the ignition to be predicted: $C C=\mathrm{HO}_{2}$ for cool flames and $C C=\mathrm{CH}_{2} \mathrm{O}$ for the hightemperature stage of the process.

- $t_{i, 1}$ is the ignition delay under transient thermodynamic conditions referred to the maximum pressure rise caused by cool flames. This ignition delay is also experimentally obtained.

- $t_{i, 2}$ is the ignition delay under transient thermodynamic conditions referred to the maximum pressure rise caused by the high-temperature stage of the combustion process. This ignition delay is also experimentally obtained.

The model used for the calculation of ignition delays under constant conditions $\left(\tau_{1}, \tau_{2}\right.$ and $\left.\tau_{C C}\right)$ and critical concentrations is a perfectly stirred reactor (PSR), which is a homogeneous closed reactor that works under constant pressure and uses the energy equation to obtain the temperature evolution. As it has been demonstrated by Payri et al. [36], this model is the most suitable to simulate ignition delays at constant thermodynamic conditions.

The model used for the calculation ignition delays under transient conditions $\left(t_{i, 1}\right.$ and $\left.t_{i, 2}\right)$ is a reciprocating internal combustion engine that operates under homogeneous conditions (IC-engine, closed 0-D reactors from 
CHEMKIN). Both, heat losses and the volume profile are imposed in order to reproduce the experimental conditions reached in the combustion chamber of the RCEM. The piston starts at bottom dead center (BDC) and a complete cycle is simulated, i.e., compression and expansion strokes. The autoignition is considered to be produced when the pressure rise rate reaches a maximum, which is the same criterion than the one used in the experiments. Therefore, the simulated results can be directly compared with the experimental ones.

Finally, the ignition delays and the critical concentrations are obtained for each thermodynamic state of the transient process with a $\Delta t$ of $10^{-5} s$, which is a compromise value between prediction accuracy and computing time. Moreover, $30 \mathrm{~s}$ have been selected as the maximum waiting time for the autoignition of the mixture under constant conditions.

\subsection{Parametric study performed}

The performed experimental study was as follows:

- Fuel: PRF25, PRF50 and PRF75.

- Initial temperature $\left(T_{i}\right): 363 \mathrm{~K}, 383 \mathrm{~K}, 403 \mathrm{~K}$ and $423 \mathrm{~K}$.

- Initial pressure $\left(P_{i}\right): 0.15 M P a$.

- Compression stroke: $180 \mathrm{~mm}$.

- Compression ratio $(C R): 14$ and 19 .

- Oxygen molar fraction $\left(\mathrm{X}_{\mathrm{O}_{2}}\right): 0.21,0.18$ and 0.16 .

- Equivalence ratio $(F r)$ : from 0.4 to 0.8 depending on the fuel and on the oxygen molar fraction. 
The performed parametric study can be seen in Table 2. The oxygen molar fraction limits the maximum working equivalence ratio in order to avoid extremely violent combustions that can damage the facility. It should be noted that the initial temperature is higher than the boiling point of the fuel, ensuring that the fuel is always in vapor phase before the beginning of the cycle.

\begin{tabular}{|c|c|c|c|c|}
\cline { 3 - 5 } \multicolumn{2}{c|}{} & \multicolumn{3}{|c|}{$X_{\mathrm{O}_{2}}$} \\
\cline { 3 - 6 } \multicolumn{2}{c|}{} & $\mathbf{0 . 2 1}$ & $\mathbf{0 . 1 8}$ & $\mathbf{0 . 1 6}$ \\
\hline \multirow{4}{*}{$T_{i}$} & $\mathbf{3 6 3}$ & $0.4,0.5,0.6$ & $0.4,0.5,0.6, \mathbf{0 . 7}$ & \\
\cline { 2 - 5 } & $\mathbf{3 8 3}$ & $0.4,0.5,0.6$ & $0.4,0.5,0.6, \mathbf{0 . 7}$ & $0.5,0.6,0.7, \underline{0.8}$ \\
\cline { 2 - 5 } & $\mathbf{4 0 3}$ & $0.4,0.5,0.6$ & $0.4,0.5,0.6, \mathbf{0 . 7}$ & \\
\cline { 2 - 5 } & $\mathbf{4 2 3}$ & $0.4,0.5,0.6$ & $0.4,0.5,0.6, \mathbf{0 . 7}$ & $0.5,0.6,0.7, \underline{0.8}$ \\
\hline
\end{tabular}

Table 2: Parametric study performed. Equivalence ratio for different initial temperatures and oxygen molar fractions. Italic.- exclusively for CR 19. Bold.- exclusively for CR 14. Underlined.- exclusively for PRF75.

\section{Results and validation}

The experimental trends of the ignition delay are discussed in this section. Besides, ignition delays calculated by solving the detailed chemical kinetic mechanism for n-heptane/iso-octane blends are compared with the experimental results in order to validate the mechanism in the working range. The experimental ignition delay predicted by means of two different methods: using the alternative integral method proposed by Desantes et al. [20] and using the Livengood \& Wu integral method. The two different exothermic 
stages of the auto-ignition process have been studied: cool flames and the high-temperature stage of the process.

\subsection{Experimental trends of the ignition delay}

Figs. 4, 5 and 6 show the ignition delay trends versus temperature for PRF25, PRF50 and PRF75, respectively, under different compression ratios and oxygen molar fractions. It can be seen that the ignition delay decreases if the temperature is increased except in the Negative Temperature Coefficient (NTC) zone [37]. Despite the fact that the NTC behavior can be smooth enough to avoid an increase of the ignition delay ( such as under $\mathrm{Fr}=0.6, \mathrm{CR}$ $=19, \mathrm{X}_{\mathrm{O}_{2}}=0.21$ for the three fuels), the ignition delay decreasing rate is usually affected by this phenomenon, changing the slope of the curve. Higher temperatures imply higher collision frequencies and collision energies and, therefore, higher specific accumulation rates of chain carriers and shorter ignition delays. During the NTC zone, the accumulation of chain carriers competes with the formation of stable long-chain olefins by the alkyl radicals, which causes a decrease of reactivity that results in longer ignition delays.

The dependence of the ignition delay on the compression ratio can be also seen in Figs. 4, 5 and 6 for PRF25, PRF50 and PRF75, respectively. The ignition delay decreases when the compression ratio is increased, since higher pressures and temperatures are reached. Moreover, Fig. 4 shows that, in general, the NTC zone becomes less pronounced if the pressure is increased. The end of the NTC zone is controlled by the unimolecular fall-off reaction $\mathrm{H}_{2} \mathrm{O}_{2}+\mathrm{M}=\mathrm{OH}+\mathrm{OH}+\mathrm{M}$, which is a third body reaction the specific reaction rate of which increases if the pressure is increased.

The effects of the equivalence ratio on the ignition delay under low tem- 

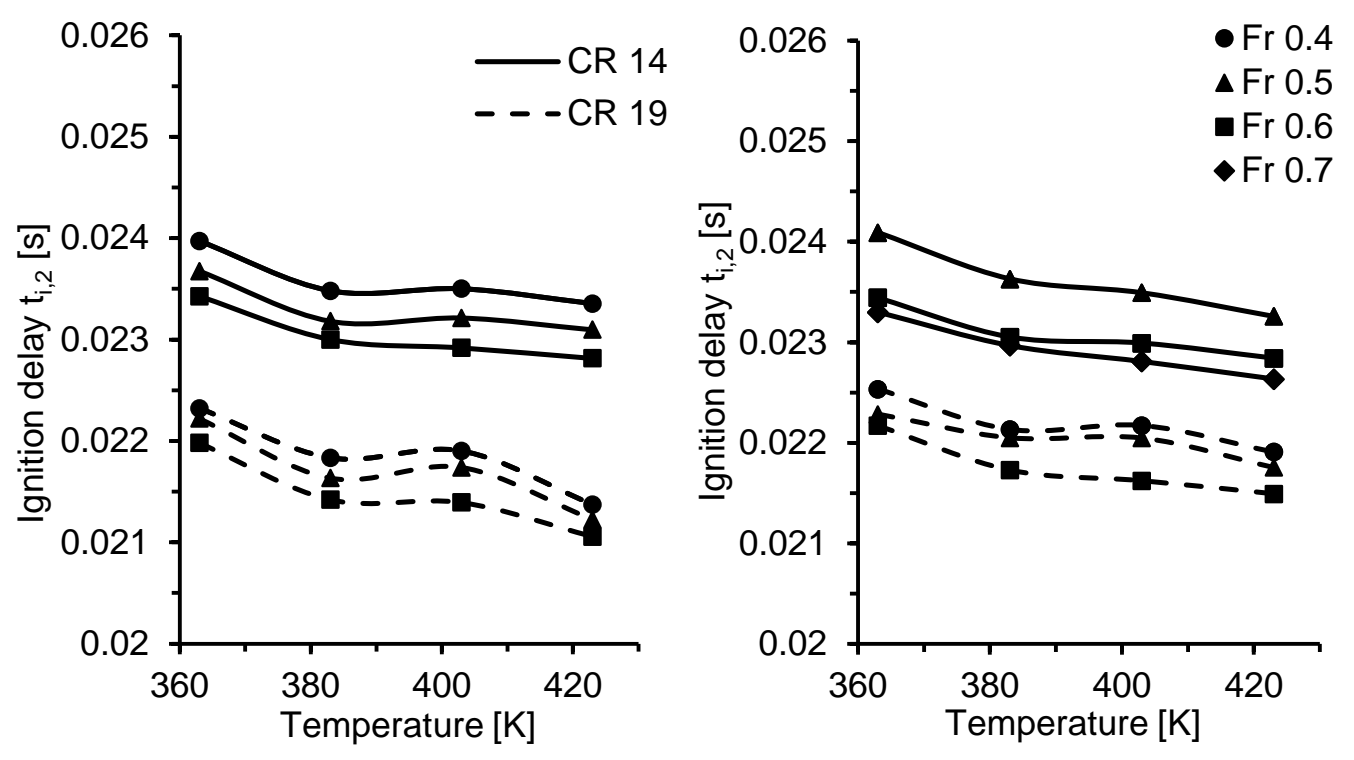

Figure 4: Ignition delay, $t_{i, 2}$, versus initial temperature for PRF25. Both compression ratios are plotted. Left.- $\mathrm{X}_{O_{2}}=0.21$. Right.- $\mathrm{X}_{O_{2}}=0.18$. 

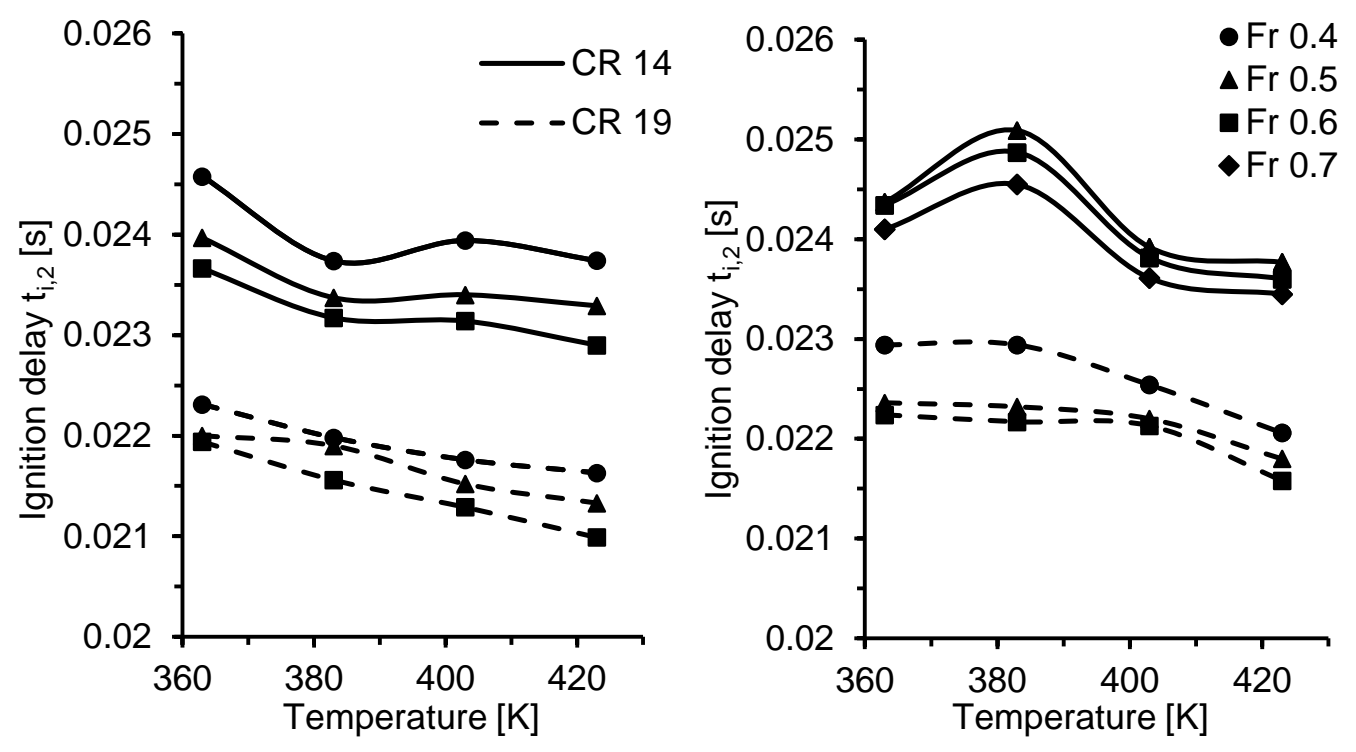

Figure 5: Ignition delay, $t_{i, 2}$, versus initial temperature for PRF50. Both compression ratios are plotted. Left.- $\mathrm{X}_{\mathrm{O}_{2}}=0.21$. Right.- $\mathrm{X}_{\mathrm{O}_{2}}=0.18$. 
perature conditions are also plotted in Figs. 4, 5 and 6 for PRF25, PRF50 and PRF75, respectively. The ignition delay referred to the high-exothermic stage of the process decrease when the equivalence ratio is increased, since ignition is triggered when a critical concentration of chain carriers is reached. The accumulation of chain carriers depends on the amount of fuel, so that the higher the equivalence ratio, the higher the generation rate of chain carriers and the shorter the ignition delay. Moreover, the lower the compression ratio or the lower the amount of oxygen, the higher the effect of the equivalence ratio on the ignition delay. I.e., the ignition delay is more sensitive to changes in the equivalence ratio if the reactivity of the mixture is reduced, since the low-temperature chain branching reactions, which depend on the amount of fuel, are more dominant. Besides, it can be seen in the figures that the NTC zone becomes less pronounced if the equivalence ratio is increased.

Fig. 7 shows the dependence of the ignition delay on the oxygen concentration. Ignition delay increases when the molar fraction of oxygen of the mixture is reduced, since lower amount of oxidizer implies lower reactivity. Moreover, the effect of the oxygen molar fraction becomes stronger if the equivalence ratio or the compression ratio are decreased. I.e. the ignition delay is more sensitive to changes in the oxygen content if the reactivity of the mixture is reduced, since the low-temperature chain branching reactions, which include the $\mathrm{O}_{2}$ addition, are more dominant. In the same way, it can be clearly seen in Fig. 5 that the NTC zone is moved to lower temperatures and it becomes more pronounced if the oxygen content is reduced.

Finally, the effects of the octane number on the ignition delay can be seen by comparison between Figs. 4, 5 and 6 . The higher the octane number, the 

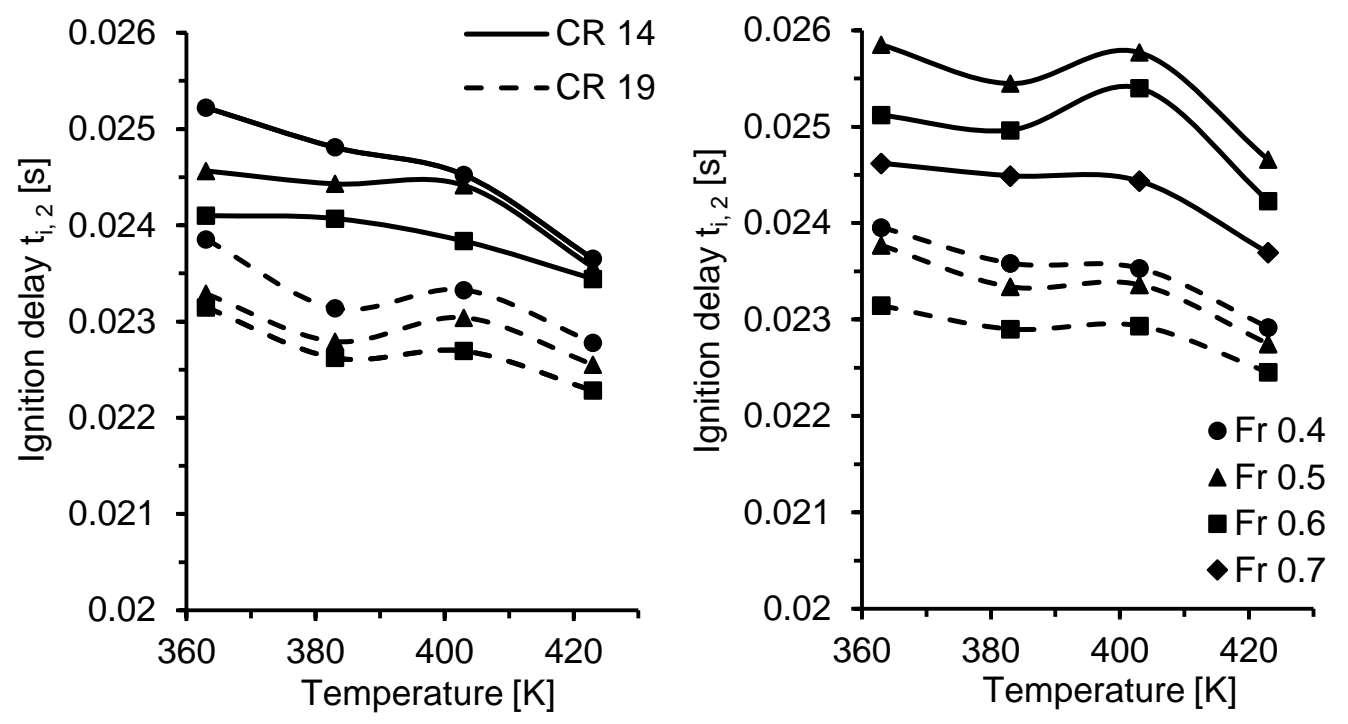

Figure 6: Ignition delay, $t_{i, 2}$, versus initial temperature for PRF75. Both compression ratios are plotted. Left.- $\mathrm{X}_{O_{2}}=0.21$. Right.- $\mathrm{X}_{O_{2}}=0.18$. 


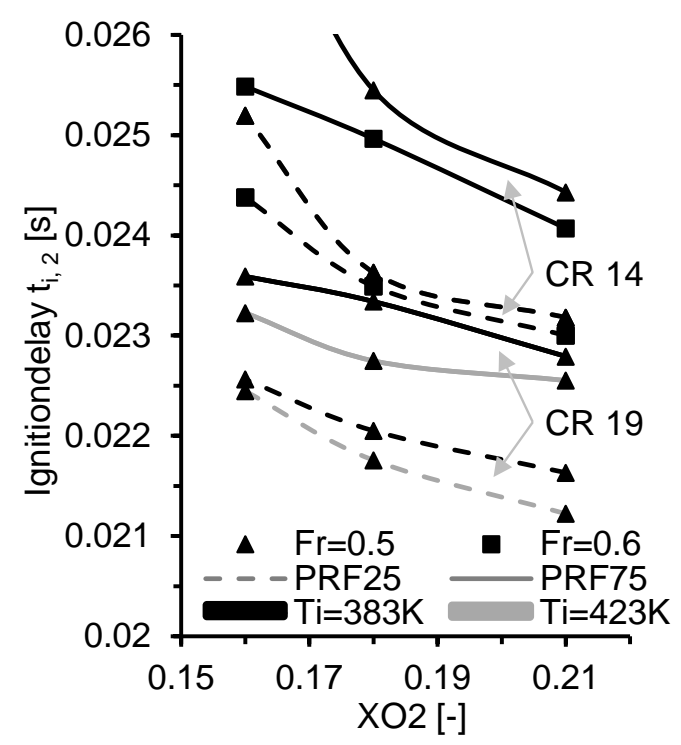

Figure 7: Ignition delay, $t_{i, 2}$, versus molar fraction of oxygen for different fuels under different conditions. Triangular marks.- $\mathrm{Fr}=0.5$. Square marks.- $\mathrm{Fr}=0.6$. Dashed line.PRF25. Solid line.- PRF75. Black line.- $\mathrm{T}_{i}=383 \mathrm{~K}$. Grey line.- $\mathrm{T}_{i}=423 \mathrm{~K}$. Both compression ratios are plotted. 
longer the ignition delay, since the octane number represents, with strong non-linearity, the resistance of a certain fuel to autoignite. Differences in octane number are reflected in differences in cool flames intensity. Higher amounts of low-temperature heat release and higher quantities of $\mathrm{H}_{2} \mathrm{O}_{2}$ are correlated with earlier ignition and lower octane values [38]. Furthermore, the fuel composition strongly affects the existence or not of a NTC behavior smooth enough to avoid a two-stage ignition pattern. In general, the higher the octane number the less prone is the fuel to show an NTC zone. Thus, the NTC behavior is a common phenomenon for alkanes. Finally, it should be noted that all fuels auto-ignite under low temperature conditions following chemical paths that include the NTC behavior. However, if the characteristic time (or relevance) of such phenomenon is short enough, it cannot be distinguish and a single-stage ignition pattern occurs.

According to cool flames, this phenomenon has shown to be highly dependent on temperature. The ignition delay referred to cool flames is always shorter if the temperature is increased. Obviously, cool flames are not affected by the loss of reactivity of the NTC behavior since it occurs before the NTC zone. Besides, the ignition delay referred to cool flames is also shorter if the compression ratio is increased, since higher temperatures and pressures are reached. Moreover, the ignition delay sensitivity to the equivalence ratio of the mixture is really low. On the one hand, the higher the equivalence ratio, the higher the reactivity of the mixture at low temperatures. However, on the other hand, the higher the equivalence ratio, the higher the heat capacity of the mixture and, therefore, the higher the thermal sink effect, leading to lower temperatures. The result of these two facts is that cool flames are 
only slightly affected by the equivalence ratio. It should be mentioned that differences in heat capacity associated to different equivalence ratios are not important enough to see any effect on the ignition delay referred to the high exothermic stage. Finally, the ignition delay referred to cool flames is also shorter if the percent of oxygen is increased.

\subsection{Validation of the detailed chemical kinetic mechanism. Predictive meth-} ods applied to cool flames

Cool flames is only present in the cases performed with PRF25 and PRF50. The high octane number and the percentage of iso-octane of PRF75 cause that cool flames cannot be clearly identified. As said before, two different predictive methods have been tested. On the one hand, the integral method defined by Eq. 2 has been applied assuming $\mathrm{HO}_{2}$ as chain carrier. On the other hand, the Livengood \& Wu integral method (Eq. 1) has been solved using $\tau_{1}$ values referred to cool flames.

The relative deviation in ignition delay, $\epsilon$, was calculated in order to more easily compare experimental and simulation results. This deviation is defined as follows:

$$
\epsilon=\frac{t_{i, 1 x}-t_{i, 1 R C E M}}{t_{\text {compression }}} 100
$$

where $t_{i, 1}$ represents the ignition delay under transient conditions referred to cool flames. The subscript $R C E M$ represents data obtained experimentally from the RCEM, whereas the subscript $x$ can represent either results obtained from a chemical simulation with CHEMKIN using an IC-engine reactor, ICE, from the alternative predictive method, Int, or from the Liven- 


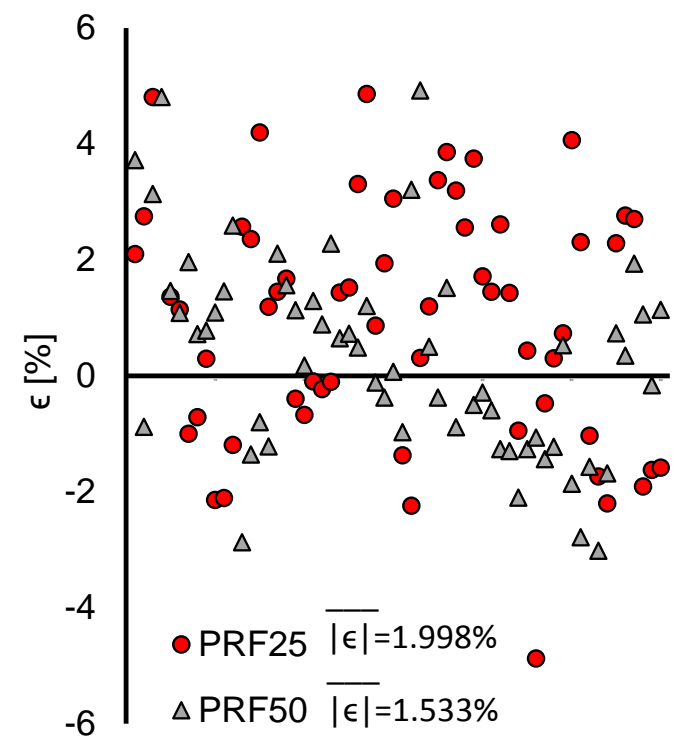

Figure 8: Percentage deviation in ignition delay referred to cool flames for PRF25 and PRF50. The mean absolute deviation, $|\bar{\epsilon}|$, shows good agreement between both experimental and simulated results.

good \& Wu integral method, $L W$. It should be noted that the previous definition for the deviation compares a difference between chemical times, $t_{i, 1 x}-t_{i, 1 R C E M}$, with the physical time of the process, $t_{\text {compression }}$. Therefore, $\epsilon$ represents the difference of the inverse of the Damköhler number of both, simulation and experiment $\left(\epsilon=1 / D a_{x}-1 / D a_{R C E M}\right)$.

The ignition delay deviations referred to cool flames between the chemical kinetic simulations and the experimental results are shown in Fig. 8 for all cases that show a two-stage ignition pattern. The mean absolute deviation, $|\bar{\epsilon}|$, has been also calculated.

The confidence intervals for the mean absolute deviation, $|\bar{\epsilon}|$, with a confidence level of $95 \%$ are equal to $[1.633,2.362] \%$ for PRF25 and to 
$[1.344,1.984] \%$ for PRF50, which means that the direct chemical simulations performed with a detailed mechanism are able to replicate the experimental ignition delays. The predicted ignition delays also show to have quite good accuracy. The confidence intervals for $|\bar{\epsilon}|$ with a confidence level of 95\% are summarized in Table 3 for the predictive methods. The values of $|\bar{\epsilon}|$ are very similar to each other, meaning that both predictive methods are able to predict the ignition delay referred to cool flames with approximately the same accuracy than the detailed chemical kinetic mechanism. Therefore, $\mathrm{HO}_{2}$ seems to be a good tracer of cool flames. Furthermore, it should be noted that the Livengood \& Wu integral method can be used to predict cool flames without having high deviations, even if a two-ignition pattern occurs.

\begin{tabular}{|r|c|c|}
\cline { 2 - 3 } \multicolumn{1}{c|}{} & PRF25 & PRF50 \\
\hline ICE & {$[1.633,2.362] \%$} & {$[1.344,1.984] \%$} \\
\hline New integral proposed & {$[1.581,2.238] \%$} & {$[1.535,2.351] \%$} \\
\hline Livengood \& Wu & {$[1.616,2.227] \%$} & {$[1.266,2.001] \%$} \\
\hline
\end{tabular}

Table 3: Confidence interval for the mean absolute deviation referred to cool flames, $|\bar{\epsilon}|$, with a confidence level of $95 \%$ for the chemical kinetic simulations (ICE) and for the different predictive methods.

Fig. 9 shows the ignition delay simulations and predictions versus the experimental ignition delay referred to cool flames. The line $y=x$ (perfect match between values), as well as the Pearson's coefficient of correlation $\left(R^{2}\right)$, has been also plotted in the figure. As it can be seen, numerical ignition delays follow an aleatory distribution around the line $y=x$, which means that ignition delay deviations are caused partly by the chemical kinetic mechanism used and partly by the experimental uncertainties mainly 

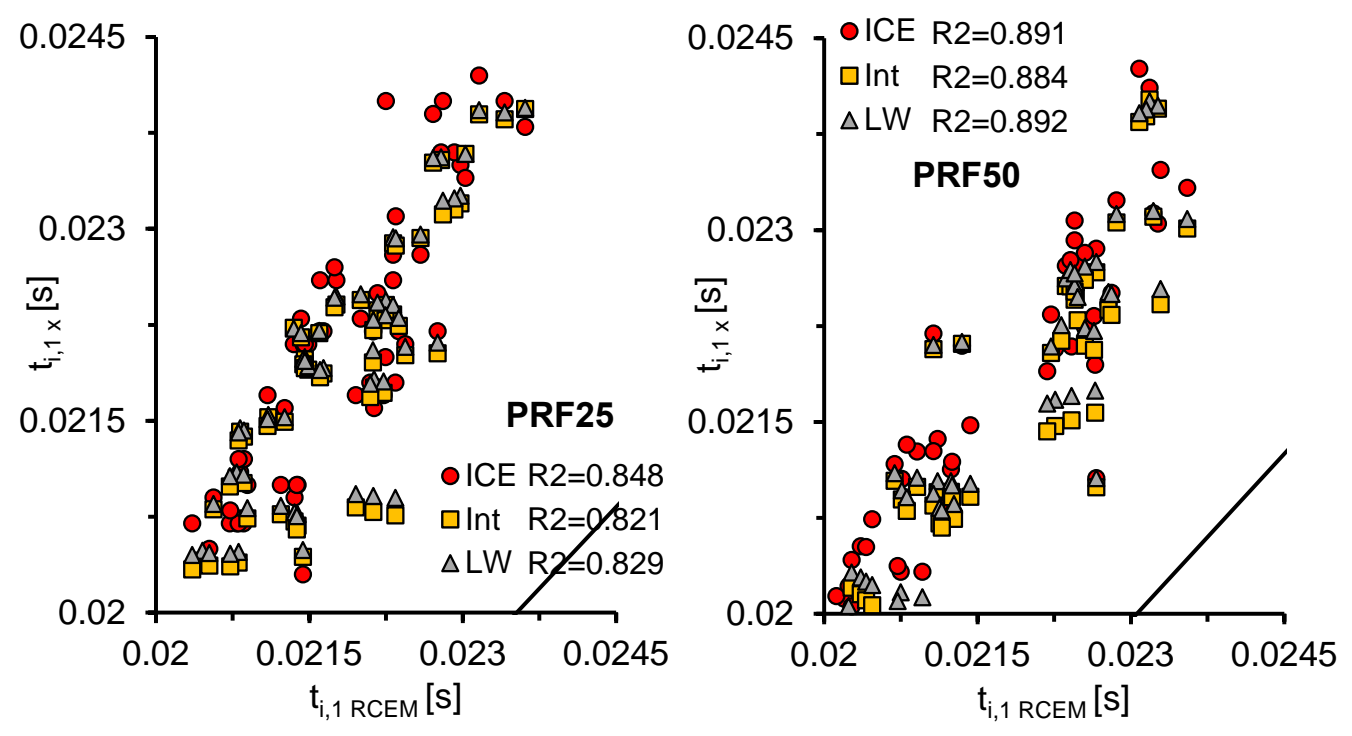

Figure 9: Ignition delay referred to cool flames, $t_{i, 1 x}$, from a chemical simulation with CHEMKIN using a closed 0-D IC-engine reactor, ICE, from the new predictive method, Int, and from the Livengood \& Wu integral method, $L W$, versus the experimental ignition delay referred to cool flames, $t_{i, 1 R C E M}$. Left.- PRF25. Right.- PRF50.

associated to the calculation of the effective volume and the heat losses in the RCEM.

3.3. Validation of the detailed chemical kinetic mechanism. Predictive methods applied to the high exothermic stage

Ignition delays referred to a maximum pressure rise rate are measured experimentally in the RCEM and calculated by direct chemical kinetic simulations in CHEMKIN. The same two different predictive methods than the ones used for cool flames have been evaluated. On the one hand, the alternative integral method proposed by Desantes et al. [20] (Eq. 2 and Eq. 3) has 
been tested, assuming formaldehyde as chain carrier. On the other hand, the Livengood \& Wu integral method (Eq. 1) has been solved by using $\tau_{2}$ values referred to a maximum pressure rise.

The percentage deviation in ignition delay, $\epsilon$, was again calculated, the definition of which is analogous to the one used for cool flames (Eq. 4). Obviously, in this case the relative deviation is calculated using the ignition delays under transient thermodynamic conditions referred to the high-temperature stage of the process.

The ignition delay deviations referred to the high-temperature stage between the chemical kinetic simulations and the experimental results are shown in Fig. 10 for all cases. The mean absolute deviation, $|\bar{\epsilon}|$, has been calculated and its value can be seen in the figure.

The confidence interval for the mean absolute deviation, $|\bar{\epsilon}|$, with a confidence level of $95 \%$ is equal to $[1.344,1.984] \%$ for PRF25, [1.809, 2.648] \% for PRF50 and $[2.463,3.765] \%$ for PRF75. It can be seen that the higher the octane number, the worse the simulation capability of the mechanism, which means that the accuracy of the n-heptane sub-mechanism is higher than the accuracy of the iso-octane sub-mechanism . The confidence intervals for $|\bar{\epsilon}|$ with a confidence level of $95 \%$ are summarized in Table 4 for all the predictive methods. The alternative predictive method tested in this paper shows to be quite accurate comparing to the experiments. However, the predictive capability of the Livengood \& Wu integral method shows a strong dependence on the type of fuel. It can be seen that the Livengood \& Wu integral is able to predict accurately the ignition delay referred to the high exothermic stage of combustion if the fuel shows a single-stage ignition (PRF75), but 


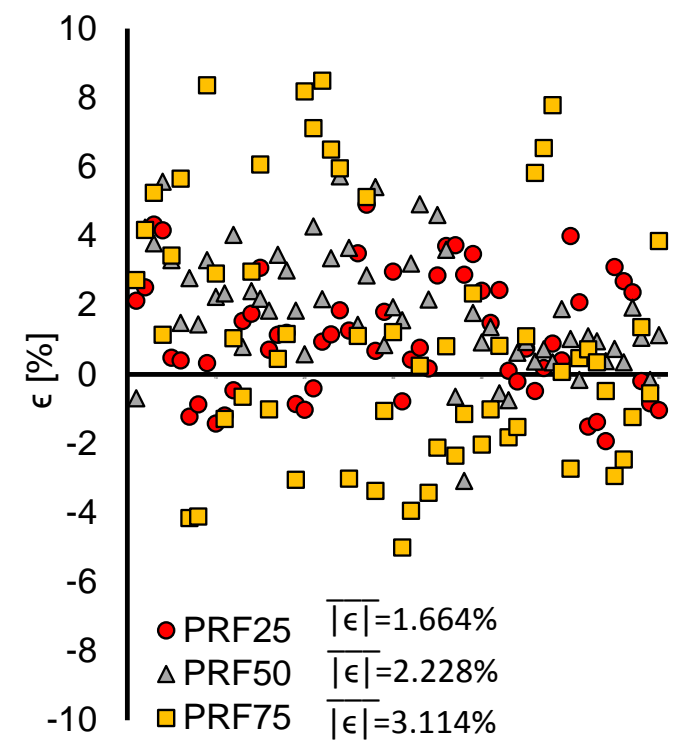

Figure 10: Percentage deviation in ignition delay referred to the high-temperature stage for all fuels. The mean absolute deviation, $|\bar{\epsilon}|$, shows a good agreement between both experimental and simulated results. 
the predictive capability is significantly reduced when a two-stage ignition occurs (PRF25 and PRF50).

\begin{tabular}{|r|c|c|c|}
\cline { 2 - 4 } \multicolumn{1}{c|}{} & PRF25 & PRF50 & PRF75 \\
\hline ICE & {$[1.344,1.984] \%$} & {$[1.809,2.648] \%$} & {$[2.463,3.765] \%$} \\
\hline New integral proposed & {$[2.061,3.424] \%$} & {$[2.635,4.018] \%$} & {$[1.740,2.477] \%$} \\
\hline Livengood \& Wu & {$[4.603,6.094] \%$} & {$[6.513,9.884] \%$} & {$[1.901,2.702] \%$} \\
\hline
\end{tabular}

Table 4: Confidence interval for the mean absolute deviation referred to a maximum pressure rise, $|\bar{\epsilon}|$, with a confidence level of $95 \%$ for the chemical kinetic simulations (ICE) and for the different predictive methods.

Only ignition delays referred to a critical concentration of chain carriers can be predicted by means of the Livengood \& Wu integral method, since one of its hypotheses is that autoignition occurs when a maximum concentration of chain carriers is reached. In the same way, all the ignition characteristics at constant conditions that are used in the integral $(\tau)$ have to be referred to a critical concentration of chain carriers. Therefore, the predictions and the ignition delays referred to the high-temperature stage are referred to different stages of the ignition process, leading to a certain deviation. Obviously, the smoother the NTC zone, the more similar the ignition delay referred to a critical concentration and referred to a maximum pressure rise rate, so that the accuracy of the Livengood \& Wu integral is increased under these conditions.

Fig. 11 shows the simulated and predicted ignition delay referred to the high-temperature stage versus the experimental measurements. The line $y=x$ (perfect match between values), as well as the Pearson's coefficient of correlation $\left(R^{2}\right)$, has been also plotted in the figure. It can be seen that 

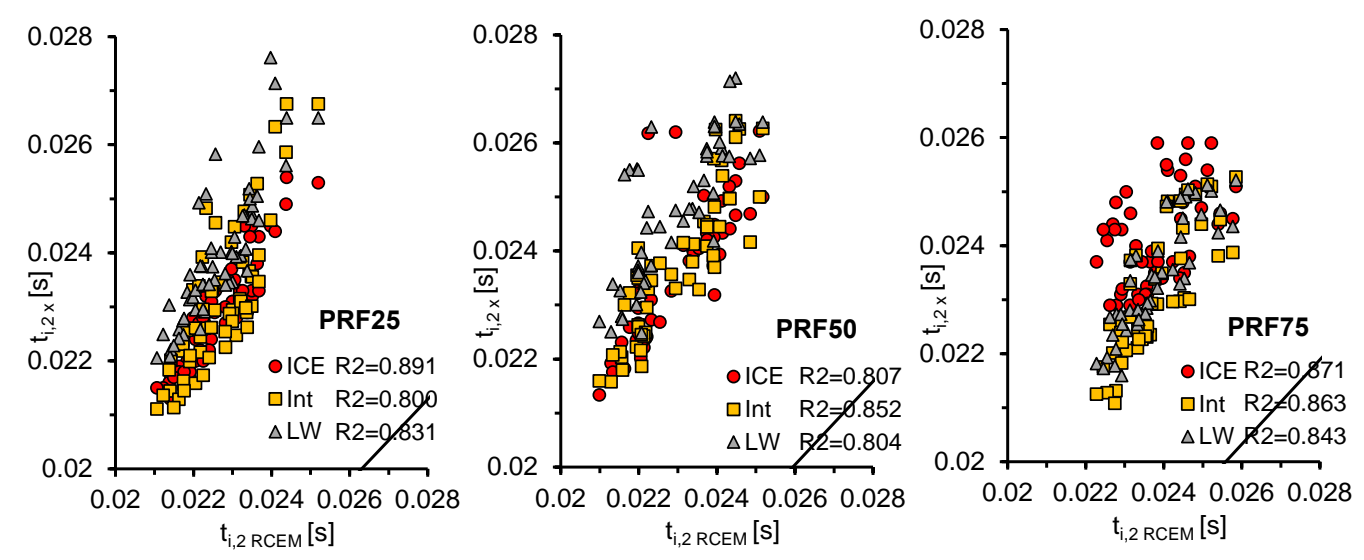

Figure 11: Ignition delay referred to the high temperature stage, $t_{i, 2 x}$, from a chemical simulation with CHEMKIN using a closed 0-D IC-engine reactor, ICE, from the new predictive method, Int, and from the Livengood \& Wu integral method, $L W$, versus the experimental ignition delay referred to the high temperature stage, $t_{i, 2 R C E M}$. Left.PRF25. Medium.- PRF50. Right.- PRF75.

the ignition delay referred to a maximum pressure rise is overestimated for PRF25 and even more overestimated for PRF50. As explained in [22], this fact can be caused by the isomerization rates of alkyl-peroxyl radicals and peroxy-alkylhydroperoxyl radicals, which have been decreased by a factor of three compared to n-heptane in the case of the iso-octane sub-mechanism. Thus, higher percentage of iso-octane implies more overestimated ignition delays. However, this trend cannot be seen for PRF75 because this phenomenon is compensated by wall effects that are not present in the simulations. Thus, the maximum pressure rise rate is reached much faster in the simulations than in the experiments, which leads to a certain negative deviation between models and experiments. The absence of wall effects and heterogeneities in CHEMKIN causes a faster pressure rise, which leads to shorter ignition 
delays and compensates the effect of the iso-octane sub-mechanism.

\section{Conclusions}

In this work a detailed chemical kinetic mechanism has been validated for PRF mixtures versus experimental results obtained from a RCEM. Besides, the alternative method to predict ignition delays under transient conditions proposed by Desantes et al. [20] has been also validated by comparison to the experiments. Both ignition delays, the one referred to cool flames and the other one referred to a maximum pressure rise rate can be predicted with quite good accuracy. Finally, the predictive capability of the method has been compared to the Livengood \& Wu integral, showing the alternative procedure better results than the classic Livengood \& Wu method.

The following conclusions can be deduced from this study:

- Both predictive methods tested in this work can predict with quite good accuracy the ignition time referred to cool flames, demonstrating that $\mathrm{HO}_{2}$ can be taken as a good cool flames tracer under a wide range of octane numbers and that the Livengood \& Wu integral method works properly for cool flames.

- The alternative integral method has shown to be able to predict the ignition delays referred to a maximum pressure rise rate when $\mathrm{CH}_{2} \mathrm{O}$ is taken as chain carrier. This ignition delay can be experimentally measured, allowing a direct comparison between predictions and experiments. 
- The high-temperature stage of the ingnition can be predicted by means of the Livengood \& Wu integral method only for fuels that do not show a two stage ignition pattern. I.e., in the present study the high exothermic stage can be predicted by this method only for PRF75, since the higher the octane number, the more prone is the fuel to show a single-stage ignition. These dependence on the type of fuel can be avoided by using the alternative integral method proposed by Desantes et al. [20]. 
580

581

$\begin{array}{ll}\text { BDC } & \text { Bottom Dead Center } \\ C C & \text { Chain carriers } \\ C F D & \text { Computational Fluid Dynamics } \\ C I & \text { Compression Ignition } \\ C R & \text { Compression Ratio } \\ E G R & \text { Exhaust Gas Recirculation } \\ F r & \text { Working equivalence ratio } \\ \text { HCCI } & \text { Homogeneous Charge Compression Ignition } \\ \text { ICE } & \text { Referred to data obtained from CHEMKIN using the internal } \\ & \text { combustion engine reactor } \\ \text { Int } & \text { Referred to data obtained from the new integral proposed in } \\ & \text { this paper } \\ L W & \text { Referred to data obtained from the Livengood \& Wu integral }\end{array}$


LTC Low Temperature Combustion

$\max \quad$ Referred to a maximum concentration of chain carriers

NTC Negative Temperature Coefficient

$P_{i} \quad$ Initial pressure

PRF Primary Reference Fuels

PSR Perfectly Stirred Reactor

RCEM Rapid Compression-Expansion Machine

SI Spark Ignition

$T_{i} \quad$ Initial temperature

TDC Top Dead Center

$t_{i} \quad$ Ignition delay under transient conditions

$t_{i, C C} \quad$ Ignition delay referred to the critical concentration of chain 589 carriers

$t_{i, 1} \quad$ Ignition delay referred to the maximum pressure rise of cool flames

$t_{i, 2} \quad$ Ignition delay referred to the maximum pressure rise

UHC Unburned hydrocarbons

$X_{O 2} \quad$ Oxygen molar fraction

$\epsilon$

Percentage deviation in ignition delay between experimental and simulation or predicted results

$|\bar{\epsilon}| \quad$ Mean absolute deviation between experimental and simulation or predicted results perature 
$\tau_{C C} \quad$ Ignition delay under constant thermodynamic conditions referred to the critical concentration of chain carriers

$\tau_{1} \quad$ Ignition delay under constant thermodynamic conditions re-

590

$\tau_{2}$ ferred to the maximum pressure rise of cool flames

Ignition delay under constant thermodynamic conditions referred to the maximum pressure rise

\section{References}

[1] J. Benajes, S. Molina, A. García, and J. Monsalve-Serrano. Effects of direct injection timing and blending ratio on RCCI combustion with different low reactivity fuels. Energy Conversion and Management, 99:193$209,2015$.

[2] Z. Zheng, L. Yue, H. Liu, Y. Zhu, X. Zhong, and M-Yao. Effect of two-stage injection on combustion and emissions under high EGR rate on a diesel engine by fueling blends of diesel/gasoline, diesel/n-butanol, diesel/gasoline/n-butanol and pure diesel. Energy Conversion and Management, 90:1-11, 2015.

[3] T. Li, D. Wu, and M. Xu. Thermodynamic analysis of EGR effects on the first and second law efficiencies of a boosted spark-ignited directinjection gasoline engine. Energy Conversion and Management, 70:130138, 2013.

[4] S.S. Nathan, J.M. Mallikarjuna, and A. Ramesh. An experimental study 
of the biogas-diesel HCCI mode of engine operation. Energy Conversion and Management, 51:1347-1353, 2010.

[5] J. Benajes, J.V. Pastor, A. García, and J. Monsalve-Serrano. An experimental investigation on the influence of piston bowl geometry on RCCI performance and emissions in a heavy-duty engine. Energy Conversion and Management, 103:1019-1030, 2015.

[6] K. Bahlouli, U. Atikol, R.K. Saray, and V. Mohammadi. A reduced mechanism for predicting the ignition timing of a fuel blend of naturalgas and n-heptane in HCCI engine. Energy Conversion and Management, 79:85-96, 2014.

[7] J.C. Livengood and P.C. Wu. Correlation of autoignition phenomena in internal combustion engines and rapid compression machines. Symposium (International) on Combustion, 5:347-356, 1955.

[8] L. Chen, T. Li, T. Yin, and B. Zheng. A predictive model for knock onset in spark-ignition engines with cooled EGR. Energy Conversion and Management, 87:946-955, 2014.

[9] M. Shahbakhti, R. Lupul, and C. R. Koch. Predicting HCCI autoignition timing by extending a modified knock-integral method. $S A E$ Paper no. 2007-01-0222, 2007.

[10] Y. Ohyama. Engine control using a combustion model. Seoul 2000 FISITA World Automotive Congress, 2000.

[11] D.J. Rausen, A.G. Stefanopoulou, J.M. Kang, J.A. Eng, and T.W. Kuo. A mean-value model for control of homogeneous charge compression 
ignition HCCI engines. Journal of Dynamic Systems, Measurement, and Control, 127:355-362, 2005.

[12] Y. Choi and J.Y. Chen. Fast prediction of start-of-combustion in HCCI with combined artificial neural networks and ignition delay model. Proceedings of the Combustion Institute, 30:2711-2718, 2005.

[13] M. Hillion, J. Chauvin, and N. Petit. Control of highly diluted combustion in diesel engines. Control Engineering Practice, 19:1274-1286, 2011.

[14] A.D.B. Yates, A. Swarts, and C.L. Viljoen. Correlating auto-ignition delays and knock-limited spark-advance data for different types of fuel. SAE Paper no. 2005-01-2083, 2005.

[15] L. Liang and R.D. Reitz. Spark ignition engine combustion modeling using a level set method with detailed chemistry. SAE Paper no. 200601-0243, 2006.

[16] R. Edenhofer, K. Lucka, and H. Kohne. Low temperature oxidation of diesel-air mixtures at atmospheric pressure. Proceedings of the Combustion Institute, 31:2947-2954, 2007.

[17] J.J. Hernandez, M. Lapuerta, and J. Sanz-Argent. Autoignition prediction capability of the Livengood-Wu correlation applied to fuels of commercial interest. International Journal of Engine Research, 15:817$829,2014$.

[18] J. M. Desantes, J. J. López, S. Molina, and D. López-Pintor. Validity of the Livengood \& Wu correlation and theoretical development of an 
alternative procedure to predict ignition delays under variable thermodynamic conditions. Energy Conversion and Management, 105:836-847, 2015.

[19] J. M. Desantes, J. J. López, S. Molina, and D. López-Pintor. Theoretical development of a new procedure to predict ignition delays under transient thermodynamic conditions and validation using a Rapid Compression-Expansion Machine. Energy Conversion and Management, 108:132-143, 2016.

[20] J. M. Desantes, , V. Bermúdez, J. J. López, and D. López-Pintor. A new method to predict high and low-temperature ignition delays under transient thermodynamic conditions and its experimental validation using a Rapid Compression-Expansion Machine. Energy Conversion and Management, 123:512-522, 2016.

[21] P.W. Bessonette, C.H. Schleyer, K.P. Duffy, W.L. Hardy, and M.P. Liechty. Effects of fuel property changes on heavy-duty HCCI combustion. SAE Paper no. 200\%-01-0191, 2007.

[22] J. M. Desantes, J.M. García-Oliver, W. Vera-Tudela, D. López-Pintor, B. Schneider, and K. Boulouchos. Study of ignition delay time and generalization of auto-ignition for PRFs in a RCEM by means of natural chemiluminescence. Energy Conversion and Management, 111:217-228, 2016.

[23] G. Barroso, A. Escher, and K. Boulouchos. Experimental and numerical investigations on HCCI combustion. SAE Paper no. 2005-24-038, 2005. 
[24] S. Schlatter, B. Schneider, Y. Wright, and K. Boulouchos. Comparative study of ignition systems for lean burn gas engines in an optically accessible Rapid Compression Expansion Machine. SAE Paper no. 201324-0112, 2013.

[25] T. Steinhilber and T. Sattelmayer. The effect of water addition on HCCI diesel combustion. SAE Paper no. 2006-01-3321, 2006.

[26] R. Payri, F.J. Salvador, J. Gimeno, and G. Bracho. A new methodology for correcting the signal cumulative phenomenon on injection rate measurements. Experimental Techniques, 32:46-49, 2008.

[27] J. M. Desantes, J. J. López, S. Molina, and D. López-Pintor. Design of synthetic EGR and simulation study of the effect of simplified formulations on the ignition delay of isooctane and n-heptane. Energy Conversion and Management, 96:521-531, 2015.

[28] J. Benajes, P. Olmeda, J. Martín, and R. Carreño. A new methodology for uncertainties characterization in combustion diagnosis and thermodynamic modelling. Applied Thermal Engineering, 71:389-399, 2014.

[29] F. Payri, S. Molina, J. Martín, and O. Armas. Influence of measurement errors and estimated parameters on combustion diagnosis. Applied Thermal Engineering, 26:226-236, 2006.

[30] G. Woschni. A universally applicable equation for the instantaneous heat transfer coefficient in the internal combustion engine. SAE Paper no. 670931, 1967. 
[31] B. Baeuerle, J. Warnatz, , and F. Behrendt. Time-resolved investigation of hot spots in the end gas of an S.I. engine by means of 2-D doublepulse LIF of formaldehyde. Symposium (International) on Combustion, 2:2619-2626, 1996.

[32] H.J. Curran, P. Gaffuri, Pitz W.J, and C.K. Westbrook. A comprehensive modeling study of n-heptane oxidation. Combustion and Flame, 114:149-177, 1998.

[33] H.J. Curran, P. Gaffuri, Pitz W.J, and C.K. Westbrook. A comprehensive modeling study of iso-octane oxidation. Combustion and Flame, 129:253-280, 2002.

[34] M. Sjoberg and J.E. Dec. An investigation into lowest acceptable combustion temperatures for hydrocarbon fuel in HCCI engines. Proceedings of the Combustion Institute, 30:2719-2726, 2005.

[35] H.J. Curran, W.J. Pitz, C.K. Westbrook, C.V. Callahan, and F.L. Dryer. Oxidation of automotive primary reference fuels at elevated pressures. Proceedings of the Combustion Institute, 27:379-387, 1998.

[36] F. Payri, X. Margot, S. Patouna, F. Ravet, and M. Funk. Use of a single-zone thermodynamic model with detailed chemistry to study a natural gas fueled Homogeneous Charge Compression Ignition engine. Energy Conversion and Management, 53:298-304, 2012.

[37] I. Glassman and R.A. Yetter. Combustion. Elsevier Academic Press, 2008. 
${ }_{719}^{6}$ [38] N. Blin-Simiand, R. Rigny, V. Viossat, S. Circan, and K. Sahetchian. Autoignition of hydrocarbon/air mixtures in a CFR engine: Experi-

721 mental and modeling study. Combustion Science and Technology, 88(56):329-348, 1993. 